Boise State University

ScholarWorks

Civil Engineering Faculty Publications and

Presentations

Department of Civil Engineering

$1-1-2019$

Evaluating Shallow Mixing Protocols as Application Methods for Microbial Induced Calcite Precipitation Targeting Expansive Soil Treatment

Bhaskar C.S. Chittoori

Boise State University

Tasria Rahman

Boise State University

Malcolm Burbank

CDM Smith

Arif Ali Baig Moghal

Telangana State 


\title{
Evaluating Shallow Mixing Protocols as Application Methods for Microbial Induced Calcite Precipitation Targeting Expansive Soil Treatment
}

\author{
Bhaskar C. S. Chittoori, Ph.D., P.E., M. ASCE \\ Assistant Professor \\ Department of Civil Engineering \\ Boise State University \\ Boise, Idaho \\ bhaskarchittoori@boisestate.edu \\ Tasria Rahman, BSCE \\ Graduate Student \\ Department of Civil Engineering \\ Boise State University \\ Boise, Idaho \\ tasriarahman@u.boisestate.edu
}

\author{
Malcolm Burbank, Ph.D. \\ Environmental Microbiologist \\ CDM Smith \\ Kellogg, Idaho \\ burbankm@cdmsmith.com \\ and
Arif Ali Baig Moghal, Ph.D., M. ASCE
Associate Professor
Department of Civil Engineering
Telangana State, India
reach2arif@gmail.com

\begin{abstract}
Expansive soils, also known as swell-shrink soils, undergo substantial volumetric changes due to moisture fluctuations from seasonal variations. These volumetric changes cause millions of dollars in damages annually. Microbial Induced Calcite Precipitation (MICP) is a promising soil improvement technique, which uses urease producing bacteria to precipitate calcium carbonate. In this study, a stabilization alternative for expansive soils was studied using MICP. Specifically, indigenous bacteria were stimulated by mixing enrichment and cementation solutions with expansive natural soils to precipitate calcium carbonate and make soil stronger and less expansive. This study examined three expansive soils with varying plasticity and mineralogical characteristics. Two protocols for shallow mixing were studied. In Protocol-1, soil samples were mixed with enrichment solutions at optimum moisture content and allowed to mellow for 1, 2, 3 , and 4 days. In Protocol-2, soil samples were mixed with enrichment solutions at moisture content corresponding to $95 \%$ of maximum dry unit weight on the wet-side of a standard Proctor curve. Moisture was allowed to escape from the mix during the mellowing period under both protocols. Following the mellowing periods, the lost moisture is replaced with cementation solution to reach optimum moisture content, and the soil sample was compacted to its maximum dry unit weight. Unconfined compression strength test was used to evaluate the strength improvements due to treatments. The treatment effectiveness was also evaluated with measurements of calcium carbonate precipitation. The results show promise for this method as an alternative to current shallow stabilization methods. An increase in mellowing period for low and medium plastic soils was determined to be beneficial. The current results also showed that the presence of higher amounts of enrichment solution and addition of less cementation solution is not advantageous for this procedure based on the performance of Protocol-2.
\end{abstract}

Keywords: MICP, expansive soils, soil stabilization, biostimulation, calcite precipitation

\section{Introduction and Background}

Expansive soils a tend to swell when moisture is increased and shrink when moisture is decreased (Nelson and Miller 1992). High plasticity clays, overconsolidated clays rich with montmorillonite clay minerals, and highly weathered shales are some examples of expansive soils (Puppala and Pedarla 2017). Expansive soils are generally found in regions with arid or semi-arid climate conditions (Hussein 2001). Forty-eight of the fifty states in the USA have expansive soils presence (Chen 1988). These soils cause severe damage to lightly loaded structures such as pavements 
This is an author-produced, peer-reviewed version of this article. The final, definitive version of this document can be found online at GeoCongress 2019: Soil Improvement, published by American Society of Civil Engineers. Copyright restrictions may apply. doi: $10.1061 / 9780784482117.025$

and residential structures, resulting in billions of dollars spent on maintenance and repair costs (Puppala et al. 2006). The estimated annual cost of damage to structures built on expansive soils in the USA increased from $\$ 2.2$ billion/year (Jones Jr and Holts 1973) to \$15 billion/year in 2012 (Jones and Jefferson 2012).

To combat the expansive soil problem, researchers over the years have developed a variety of methods. Petry and Little (2002) discussed several of these stabilization methods, including mechanical compaction, chemical stabilization, pre-wetting, moisture barriers, lime injections, and deep soil mixing. There are several application methods to stabilize expansive soils chemically. These can be broadly classified as (1) shallow stabilization, (2) deep soil mixing, and (3) injection. Subgrade stabilization under roadways generally uses shallow stabilization method (Puppala and Pedarla 2017). Unfortunately, even after shallow stabilization, sometimes subgrades tend to fail. This can be attributed to (a) loss of stabilizer over time, or (b) ineffective stabilizer selection. In addition to this possible ineffectiveness, traditional stabilization techniques may be harmful environmentally - mainly when using additives such as lime or Portland cement. These additives may leach into the environment and increase adjacent soil $\mathrm{pH}$, and they are known to generate high carbon emissions, which may contribute to climate change. For all these reasons, it would be beneficial if a more environment friendly method is available to stabilize expansive soils. One such innovative alternative uses microorganisms, either naturally present in the subsurface soils or augmented, to precipitate calcium carbonate and improve the engineering properties of soils (DeJong et al. 2006). This method is known as Microbial Induced Calcite Precipitation (MICP).

In MICP, ureolytic bacteria such as Sporosarcina pasteurii catalyze the hydrolysis of urea to produce ammonium and carbonate ions (Eq. 1). With the addition of $\mathrm{Ca}^{2+}$ ion, calcium carbonate crystals form on the cell wall of the bacteria (Burne and Chen 2000).

$$
\begin{aligned}
& \mathrm{CO}\left(\mathrm{NH}_{2}\right)_{2}+2 \mathrm{H}_{2} \mathrm{O} \rightarrow 2 \mathrm{NH}_{4}{ }^{+}+\mathrm{CO}_{3}{ }^{2-} \\
& \mathrm{Ca}^{2+}+\mathrm{CO}_{3}{ }^{2-} \rightarrow \mathrm{CaCO}_{3}
\end{aligned}
$$

The microbially induced calcium carbonate bridges adjacent soil particles and increases the shear strength and stiffness of soil and decreases permeability (van Paassen et al. 2010; Cheng and Cord-Ruwisch 2014). The primary factors affecting calcite precipitation are calcium ion concentration, dissolved inorganic carbon concentration, $\mathrm{pH}$ and availability of nucleation sites (Hammes and Verstraete 2002). There are two methods to apply MICP: bioaugmentation and biostimulation.

In bioaugmentation, exogenous bacteria are added to soil to precipitate calcite. The applications of this process have shown promising results in diverse fields including, improvement of concrete strength and durability (De Muynck et al. 2008); mitigation of sand liquefaction (Montoya et al. 2012); and sand impermeability (Nemati and Voordouw 2003). Mostly, researchers have applied bioaugmentation on sandy and silty type soil using urease producing bacteria (Whiffin et al. 2007; van Paassen et al. 2010). Chittoori and Neupane (2018) studied the application of bioaugmentation to mitigate expansive soil swelling and noted that low to medium plastic soils can be effectively treated using MICP via bioaugmentation. However, bioaugmentation may not be effective in all cases as it is dependent on the augmented bacteria to adjust to the new environment and compete with native microorganisms, which affect the survival rate and metabolic potential of the augmented bacteria (Wenderoth et al. 2003). Van Veen et al. (1997) observed that the survivability of exogenous microorganisms after introducing into a new environment, tend to decline rapidly and rarely propagate. Another issue with bioaugmentation is the uneven distribution of bacteria and clogging near the inlet were observed in this method (Stocks-Fischer et al. 1999). The need for injecting nonnative bacterial strains into soil has limited the technology from becoming a cost-effective approach (Gomez et al. 2018).

In case of the biostimulation, indigenous bacteria are used to achieve calcite precipitation (Burbank et al. 2011a). This method has essential economic and environmental benefits through the elimination of expensive non-native monoclonal bacterial cultivation and injection into natural soil ecosystems. These natural ureolytic microbes are more resilient in their native environment than the injected strains which result in uniform distribution of calcite and sustained enzymatic capabilities (Gomez et al. 2018). Usually, the number of bacteria per gram of natural soils is $10^{6}$ to $10^{12}$ (Boquet E, Boronat A 1973; Torsvik et al. 1990). Boquet et al. (1973) showed that all soil bacteria could precipitate calcite. Also, it is possible to increase their number in a variety of soils through biostimulation with calcite precipitation (Burbank et al. 2011b). Burbank et al. (2011) first demonstrated the ability of native ureolytic microorganisms to hydrolyze urea and induce calcite precipitation in liquid media using ureolytic strains obtained from the Eastern Snake River. Gomez et al. (2014) demonstrated the ability of stimulation techniques to enable calcite precipitation in granular soils, using one-dimensional column specimens which resulted in significant improvement of geotechnical properties, including unconfined compressive strength and permeability. Chittoori et al. 2018 
evaluated the effectiveness of the biostimulation approach to treating natural expansive soils using an injection system. They reported a significant reduction in swelling strain and increased in unconfined strength after one treatment cycle. Chittoori et al. (2018) study is an initial step in establishing an alternative treatment protocol for expansive soils. Biostimulation using the ureolytic bacteria present in the soil is becoming a preferred method of application for MICP.

In order to stimulate the ureolytic bacteria present in the soil and precipitate calcite, substrate solutions must pass through the soil. In the case of clayey soils, percolating or flushing under gravity is not practical due to the low permeability of these soils. Hence, injecting under high pressures is a viable alternative. This approach was studied by Chittoori et al. (2018), who found that calcite precipitation is possible by injecting treatment solutions at high pressures into expansive soils. However, in the case of shallow treatment methods for pavement applications, injecting at high pressures could be counterproductive, as higher pressures can fracture the soil or heave pavement. Hence, in this study, an MICP application method is investigated by mixing substrate solutions into the soil similar to lime or cement stabilization. Two different protocols were studied on three different soils to evaluate their feasibility in precipitating calcium carbonate and increasing the strength of the soil. This paper presents the results obtained from this study.

\section{Materials and Methods}

Three soils with varying plasticity characteristics were studied to evaluate the effectiveness of MICP in mitigating expansive soil swelling studied. One of the three soils was a naturally occurring expansive soil obtained from Marsing, Idaho along highway US-95 near milepost 16.0. This soil was denoted as C-70. The 70 indicates the percentage of clay present in the soil. C-70 soil had a liquid limit of 111 and a plasticity index of 71 which classifies it as a high swelling soil. The remaining two soils were alterations of the C-70 soil to minimize the clay content and correspondingly the swelling capabilities. The clay content in the soil was minimized by adding different percentages of medium to fine sand bringing the clay content of the artificial soils to $40 \%$ and $30 \%$ and denoted as C- 40 and C30, respectively. All three soils were tested for various geotechnical engineering properties including Atterberg limits, maximum dry unit weight (MDUW) and optimum moisture content (OMC), specific gravity, 1-D swell strain, swell pressure, and unconfined compression strength (UCS).

Table 1: Baseline Data for the Two Natural Soils Tested in This Research

\begin{tabular}{lllllllll}
\hline \hline & & & & & & 1-D \\
Soil & $\begin{array}{l}\text { LL } \\
\text { Type }\end{array}$ & $\begin{array}{l}\text { PI } \\
(\%)\end{array}$ & $\begin{array}{l}\text { Specific } \\
\text { Gravity }\end{array}$ & $\begin{array}{l}\text { MDUW } \\
\left(\mathrm{kN} / \mathrm{m}^{3}\right)\end{array}$ & $\begin{array}{l}\text { OMC } \\
(\%)\end{array}$ & $\begin{array}{l}\text { UCS } \\
(\mathrm{kPa})\end{array}$ & $\begin{array}{l}\text { Swell } \\
\text { Strain } \\
(\%)\end{array}$ & $\begin{array}{l}\text { Swell } \\
(\mathrm{kPa})\end{array}$ \\
\cline { 2 - 9 } & ASTM & ASTM & ASTM & & ASTM & ASTM & \\
& D4318 & D854 & D698 & & D2166 & D4546 & \\
\hline \hline C-70 & 111 & 71 & 2.53 & 11.04 & 32.6 & 155.1 & 17.9 & 287 \\
C-40 & 62 & 41 & 2.66 & 13.98 & 28.5 & 88.2 & 9.14 & 179 \\
C-30 & 43 & 19 & 2.6 & 15.65 & 21.5 & 69.6 & 2.58 & 70 \\
\hline \hline
\end{tabular}

Note: LL-Liquid limit; PL-Plasticity Index; MDUW-Maximum Dry Unit Weight; OMC-Optimum Moisture Content; UCSUnconfined Compression Strength

\section{Treatment Solutions}

Two types of treatment solutions were used in this research to achieve biomineralization: enrichment solution and cementation solution. Enrichment solutions contained both carbon and nitrogen sources along with other necessary nutrients to facilitate bacterial growth. As recommended by Burbank et al. (2011), the enrichment solutions consisted of $100 \mathrm{mM}$ of Sodium Acetate, $333 \mathrm{mM}$ of Urea and $0.5 \mathrm{~g} / \mathrm{L}$ of Corn Steep Liquor (CSL). Corn steep liquor consisted of amino acids, vitamins, and minerals and was provided in both enrichment solution and cementation solution (Burbank et al. 2011a) and is necessary for microorganism survival. This cementation solution differed from the enrichment solution only by the calcium presence which facilitated calcium carbonate precipitation. Consequently, the cementation solution consisted of $100 \mathrm{mM}$ of sodium Acetate, $333 \mathrm{mM}$ of Urea, $0.5 \mathrm{~g} / \mathrm{L}$ of Corn Steep Liquor (CSL) along with $250 \mathrm{mM}$ of Calcium Chloride. 


\section{$\underline{\text { Treatment Protocols }}$}

Two protocols were studied to achieve calcite precipitation by mixing the enrichment and cementation solutions into the soil. In Protocol-1, soil samples were mixed with the same volume of enrichment solutions corresponding to an optimum moisture content from the Standard Proctor test. After mixing, the samples were allowed to hydrolyze urea for different periods of time (1, 2, 3, and 4 days). These periods were called mellowing periods, as per the shallow stabilization jargon which identifies the period between mixing and sample compaction (for curing) in chemical stabilization protocols. During the mellowing period, the samples are left on the countertop to allow moisture loss. After completion of the certain mellowing period, the amount of enrichment solution lost was replaced with cementation solution to bring the overall moisture of the sample equal to the optimum moisture content. The soil was compacted into a UCS sample of dimensions $7.1 \mathrm{~cm}$ in diameter and $14.2 \mathrm{~cm}$ in height. After preparing the sample, the UCS test was performed on the compacted samples as per ASTM D2166. After performing the UCS test, a small portion of the tested soil sample was taken to measure the calcium carbonate content according to ASTM D4373. As per ASTM D 4373, a simple portable device was used to carry out this gasometric method of carbonate content determination. This device consisted of a reaction cylinder which contained a small cup filled with $1 \mathrm{~N}$ hydrochloric acid $(\mathrm{HCl})$ and a pressure gauge. Initially, the soil samples were poured into the reaction cylinder, and $20 \mathrm{ml}$ of $\mathrm{HCl}$ was placed inside the chamber in the small cup provided. The reaction cylinder was closed tight, and the small cup was tilted to initiate the reaction between the $\mathrm{HCl}$ and soil sample. Due to this reaction carbon dioxide was released and pressurized the cylinder. This pressure was recorded using the pressure gauge located on the device. Figure 1 presents a photographic representation of the treatment procedure.

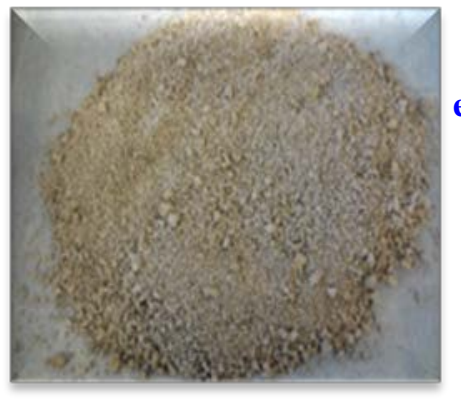

Preparation of soils

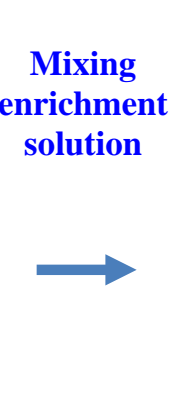

$$
\begin{gathered}
\text { Soils during a mellowing } \\
\text { period }
\end{gathered}
$$

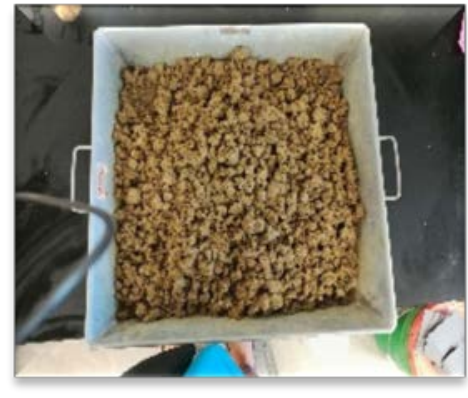

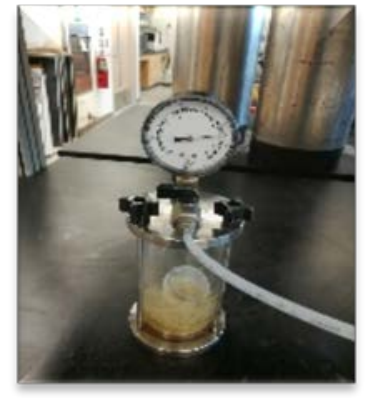

Determination of calcium carbonate
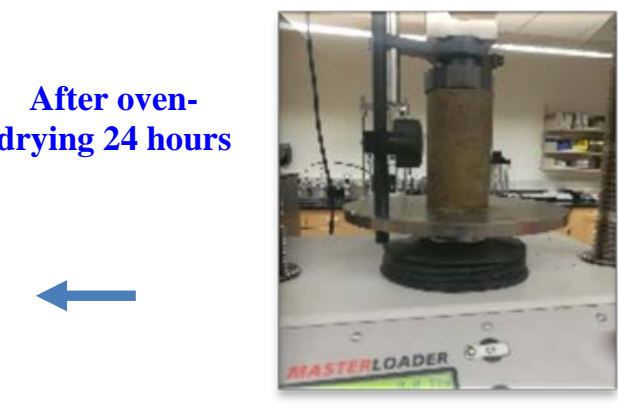

Testing samples with UCS machine

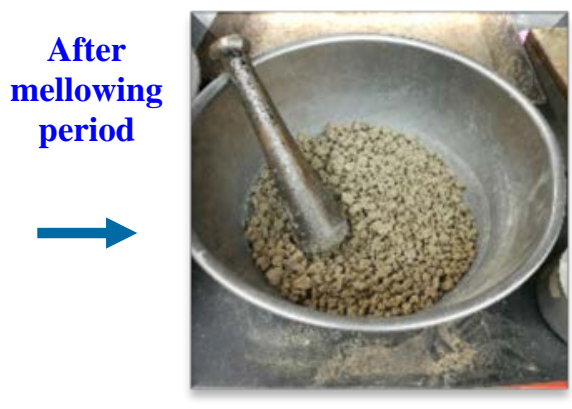

Preparation of soils after mellowing periods

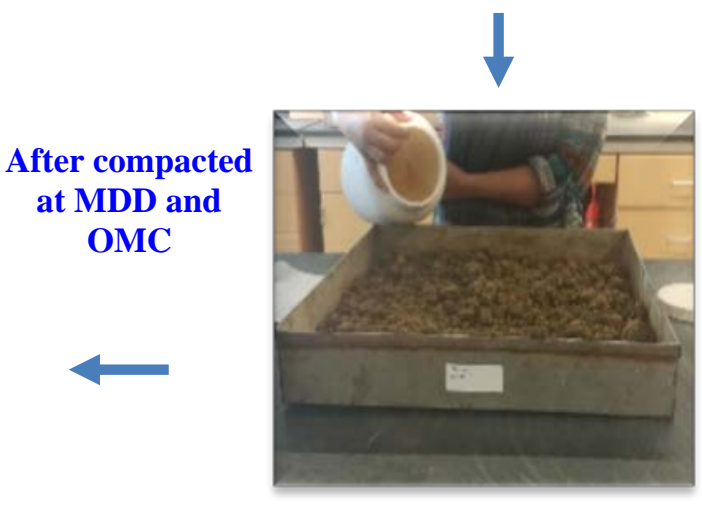

Mixing of cementation solution

Figure 1: Photographic representation of a typical treatment process 
In these two protocols, samples prepared for the UCS test were not cured. UCS tests were performed on the sampels immediately after preparation. The procedure for Protocol-2 was identical to Protocol-1 except for the initial volume of enrichment solution which corresponded to the moisture content at 95\% of MDUW on the wet-side of the standard Proctor curve in place of OMC.

\section{Results and Discussion}

Both UCS and calcite content tests were performed on treated and untreated soils to evaluate strength changes and calcite precipitation after treatments. Table 2 and Table 3 present a summary of these results for Protocol- 1 and Protocol-2. Both protocols involved the same number of mellowing periods ranging from one to four days. The mellowing periods are denoted as 'MP'. MP-1 denotes a mellowing time of one day, MP-2 denotes a mellowing time of two days and so on.

Table 2 Summary of UCS and Calcite tests data for Protocol-1

\begin{tabular}{|l|r|r|r|r|r|r|r|r|}
\hline & \multicolumn{4}{|c|}{ UCS (kPa) } & \multicolumn{3}{|c|}{ Calcite Concentration (\%) } \\
\cline { 2 - 9 } Soil Type & MP-1 & MP-2 & MP-3 & MP-4 & MP-1 & MP-2 & MP-3 & MP-4 \\
\hline C-30 & 97.3 & 111.5 & 139.0 & 174.8 & 0.71 & 0.9 & 1.01 & 1.12 \\
\hline C-40 & 96.4 & 103.1 & 123.5 & 167.0 & 0.73 & 0.83 & 0.9 & 1.1 \\
\hline C-70 & 183.6 & 228.7 & 141.7 & 127.7 & 0.99 & 1.08 & 0 & 0 \\
\hline
\end{tabular}

Table 3 Summary of UCS and Calcite tests data for Protocol-2

\begin{tabular}{|l|r|r|r|r|r|r|r|r|}
\hline & \multicolumn{4}{|c|}{ UCS (kPa) } & \multicolumn{3}{|c|}{ Calcite Concentration (\%) } \\
\cline { 2 - 9 } Soil Type & MP-1 & MP-2 & MP-3 & MP-4 & MP-1 & MP-2 & MP-3 & MP-4 \\
\hline C-30 & 76.1 & 100.2 & 120.5 & 158.4 & 0.34 & 0.78 & 0.95 & 1.04 \\
\hline C-40 & 91.0 & 97.0 & 112.9 & 142.6 & 0.53 & 0.73 & 0.85 & 0.99 \\
\hline C-70 & 154.9 & 124.1 & 114.3 & 109.4 & 0.95 & 0 & 0 & 0 \\
\hline
\end{tabular}

\section{Unconfined Compression Test}

Figure 2 presents UCS variation with mellowing periods for all three soils. Figure 2(a) presents the UCS results for Protocol-1 while Figure 2(b) presents the same for Protocol-2. Both Figure 2(a) and 2(b) showed untreated UCS values for all three soils. Please note that the untreated C-70 soil showed highest UCS value of $155 \mathrm{kPa}$ and C-30 showed the lowest value of $69.6 \mathrm{kPa}$. Although C-30 soil had higher sand content, the strength was lower due to the unconfined nature of the test.

It can be observed from Figure 2(a) that for both C-30 and C-40 soils, the increase in the mellowing period appears to increase UCS. This could be due to the formation of calcium carbonate in the void spaces between particles which bonds particles and increases strength. However, for C-70 soil the UCS increased after MP-1 and MP-2 and reduced for MP-3 and MP-4. This reduction in strength after three and four mellowing periods for C-70 soil could be due to bacteria becoming dormant after two days of mellowing and forming pores which may not have resulted in calcite precipitation. Although cementation solutions contained nutrients for bacteria, since the UCS test was conducted immediately after mixing there was not sufficient time to hydrolyze urea and precipitate calcite. Further testing is underway to confirm this hypothesis. 


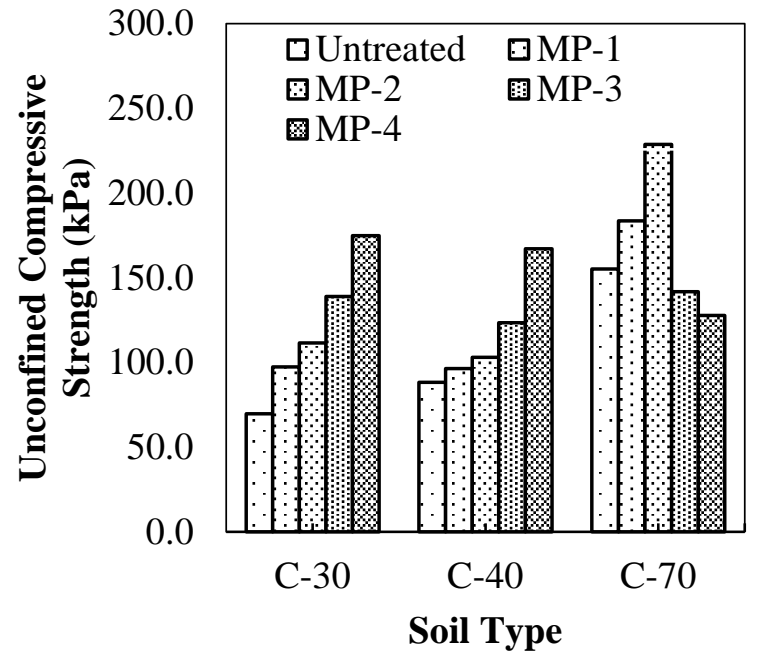

(a)

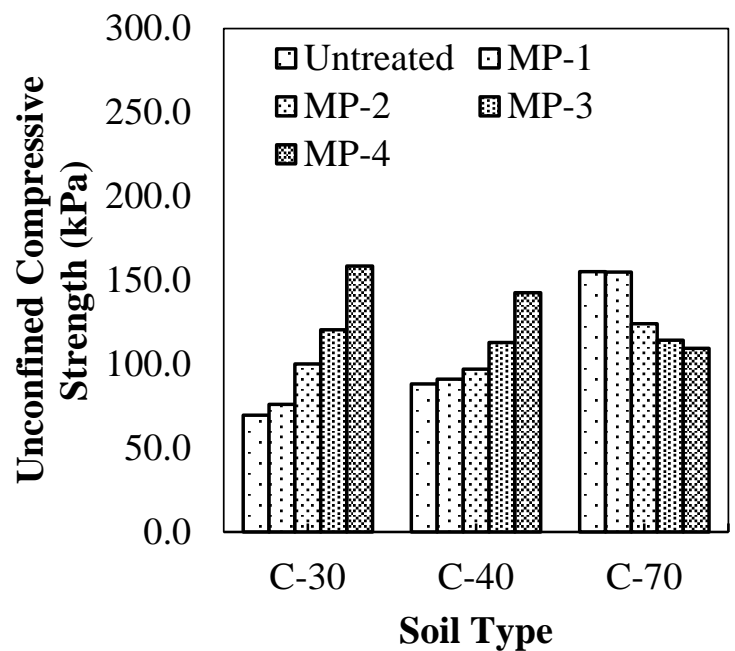

(b)

Figure 2 Variation of UCS values with mellowing periods for both protocols (a) Protocol-1 (b) Protocol-2

Figure 3 shows the percentage change in UCS of all three soils between the protocols. This percentage change is compared with the untreated strength of the soil. It can be noted from Figure 3(a) and 3(b) that Protocol-1 performed slightly better than Protocol-2. Nevertheless, both protocols increased the UCS values. In the case of C-70 soil, from Figure 3(c), it can be noticed that Protocol-2 did not perform well for any of the mellowing periods. This could be due to the addition of less cementation solution after mellowing periods to bring up the moisture content up to OMC. Currently, testing is underway to extend the mellowing periods beyond four days.

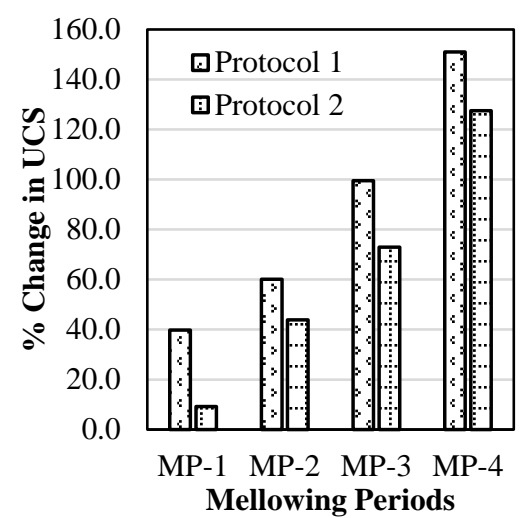

(a)

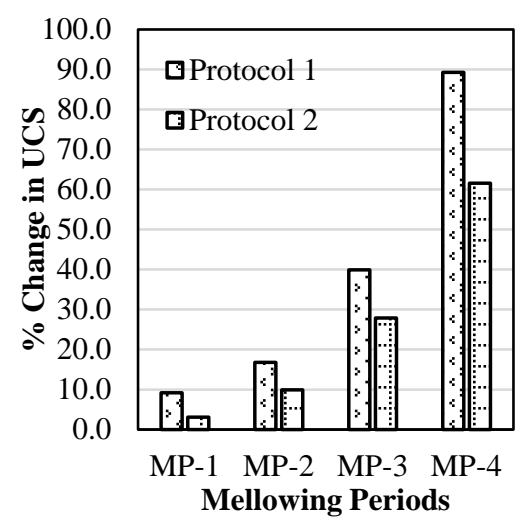

(b)

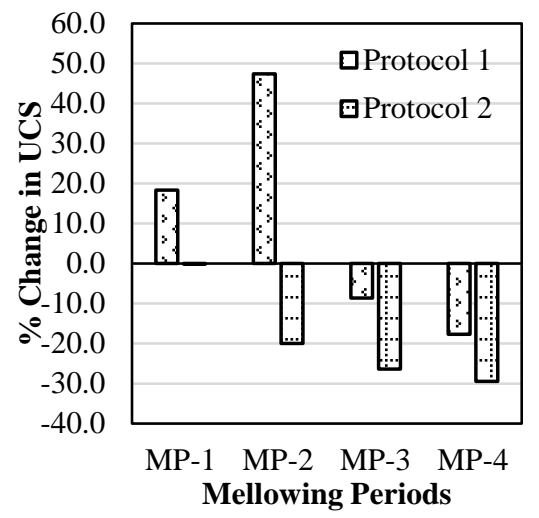

(c)

Figure 3 Comparison of the percentage change in UCS between protocols for all three soil types (a) C-30 Soil, (b) C-40 Soil, (c) C-70 Soil

\section{Calcium Carbonate Test}

All soil samples were tested for the presence of calcium carbonate before and after treatments to confirm that the increase in strength observed was related to calcite precipitation. Visual inspection of the sample after UCS tests showed that that precipitated calcite was uniform across the sample which implied that bacteria and substrate solution were present uniformly in the soil sample. Figure 4 presents the calcite concentration for both protocols. It should be noted here that the calcite reported is a percentage of the dry weight of soil. It can be observed from Figure 4(a) that calcite precipitation increased with the increase in the mellowing period for C-30 and C-40 soils for Protocol- 1. However, for C-70 soil calcite precipitation increased for MP-1 and MP-2 but was absent in MP-3 and MP-4 samples. This is corroborating the UCS observations, and the reasons for this could be similar to the ones explained in the UCS 
section of this paper. In case of Protocol-2, as presented in Figure 4(b), calcite precipitation was evident in both C-30 and C-40 soils, but C-70 soil did not have any calcite precipitation after MP-1. Further testing is underway to measure urease activity of these soils to understand why calcite is not precipitating after for MP-2, MP-3, and MP-4 cases. These results will be discussed in future publications.

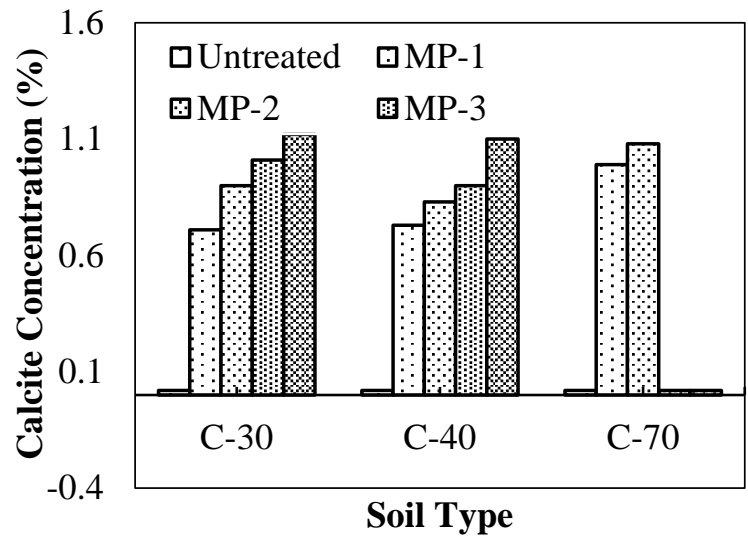

(a)

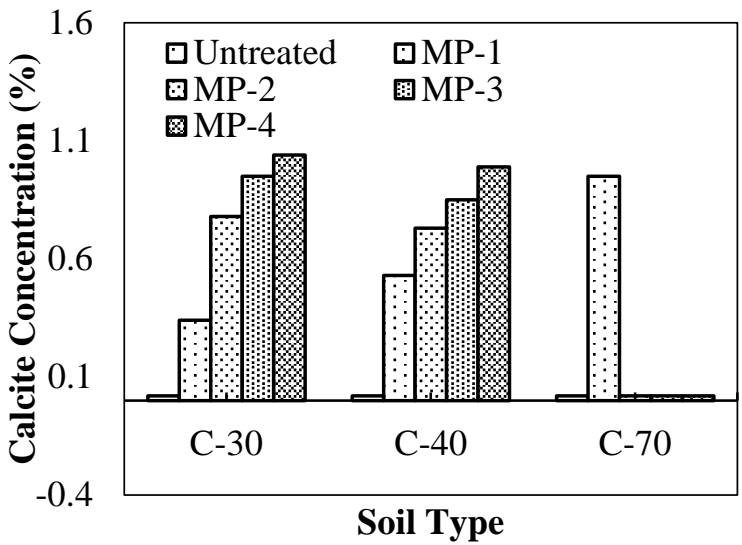

(b)

Figure 4 Variation of calcite concentration with mellowing periods for both protocols (a) Protocol-1 (b) Protocol-2

\section{Summary and Findings}

Experiments were conducted to study the effectiveness of shallow mixing protocols to apply MICP technique to stabilize expansive soils. Two protocols were applied to three soils with varying plasticity characteristics, and their performance was measured using UCS and Calcite precipitation tests. Protocol-1 performed slightly better than Protocol-2 for all three soils. C-30 and C-40 soils showed improvement in strength with increase in mellowing periods. This improvement in strength was correlated to calcite precipitation in these soils. However, for C-70 soil, the UCS increased for one and two days of mellowing but decreased for three and four days of mellowing. The current results showed that the presence of higher amounts of enrichment solution and addition of less cementation solution is not advantageous for this procedure based on the performance of Protocol-2. Also, in addition to this, an increase in mellowing periods for low and medium plastic soils (C-30 and C-40) was beneficial. However, the mellowing period beyond two days was not beneficial for high plastic soil (C-70). This could be due to bacteria becoming dormant after two days of mellowing in soils with high plasticity due to the hydrophilic nature of these soils. Further testing is underway to measure urease activity of these soils to understand why calcite is not precipitating after for MP-2, MP3 , and MP-4 cases. These results will be discussed in future publications.

\section{REFERENCES}

ASTM D2166 / D2166M-16, Standard Test Method for Unconfined Compressive Strength of Cohesive Soil, ASTM International, West Conshohocken, PA, 2016.

ASTM. (2000). "D854 - Standard Test Methods for Specific Gravity of Soil Solids by Water Pycnometer.” Astm D854, 2458000(C), 1-7.

ASTM D4318, ASTM D 4318-10, and D4318-05, A. (2005). "Standard Test Methods for Liquid Limit, Plastic Limit, and Plasticity Index of Soils.” Report, 04(March 2010), 1-14.

ASTM D4546-96. (1996). "Standard Test Methods for One-Dimensional Swell or Settlement Potential of Cohesive.” Astm International, 1-7.

ASTM D698. (1933). "Standard Test Methods for Laboratory Compaction Characteristics of Soil Using Standard Effort.” ASTM International, 3.

Boquet E, Boronat A, R.-C. A. (1973). "Production of calcite (calcium carbonate) crystals by soil bacteria is a general phenomenon.” Nature, 246, 527-529. 
This is an author-produced, peer-reviewed version of this article. The final, definitive version of this document can be found online at GeoCongress 2019: Soil Improvement, published by American Society of Civil Engineers. Copyright restrictions may apply. doi: $10.1061 / 9780784482117.025$

Burbank, M. B., Weaver, T. J., Green, T. L., Williams, B. C., and Crawford, R. L. (2011a). "Precipitation of Calcite by Indigenous Microorganisms to Strengthen Liquefiable Soils.” Geomicrobiology Journal, 28(February), 301-312.

Burbank, M. B., Weaver, T. J., Williams, B. C., and Crawford, R. L. (2011b). "Urease activity of ureolytic bacteria isolated from six soils in which calcite was precipitated in indigenous bacteria." Geomicrobiology Journal, In Press.

Burne, R. A., and Chen, Y. Y. M. (2000). “Bacterial ureases in infectious diseases.” Microbes and Infection.

Chen, F. H. (1988). Foundation on Expansive soils. Elsevier Science, Amsterdam, The Netherlands.

Cheng, L., and Cord-Ruwisch, R. (2013). "Upscaling Effects of Soil Improvement by Microbially Induced Calcite Precipitation by Surface Percolation.” Geomicrobiology Journal, Taylor \& Francis, null-null.

Chittoori, B. C. S., Burbank, M., and Islam, M. T. (2018). "Evaluating the Effectiveness of Soil-Native Bacteria in Precipitating Calcite to Stabilize Expansive Soils.” IFCEE, Orlando, FL, 5-10.

Chittoori, B., and Neupane, S. (2018). "Evaluating the Application of Microbial Induced Calcite Precipitation Technique to Stabilize Expansive Soils.” GeoChina, HangZhou, China.

D2166, A. (2016). "Standard Test Method for Unconfined Compressive Strength of Cohesive Soil 1." Current, 04.

DeJong, J. T., Fritzges, M. B., and Nüsslein, K. (2006). "Microbially induced cementation to control sand response to undrained shear.” Journal of Geotechnical and Geoenvironmental Engineering, 132(11), 1381-1392.

Gomez, M. G., Graddy, C. M. R., DeJong, J. T., Nelson, D. C., and Tsesarsky, M. (2018). "Stimulation of native microorganisms for biocementation in samples recovered from field scale treatment depths.” Journal of Geotechnical and Geoenvironmental Engineering.

Hammes, F., and Verstraete, W. (2002). "Key roles of $\mathrm{pH}$ and calcium metabolism in microbial carbonate precipitation." Reviews in Environmental Science and Biotechnology, 1(1), 3-7.

Hussein, E. A. (2001). “Viscoplastic Finite Element Model for Expansive Soils.” Electronic Journal of Geotechnical Engineering paper, 122.

Jones Jr, D. E., and Holts, W. G. (1973). “Expansive Soils - The Hidden Disaster.” American Society of Civil Engineers, 43(8), 49-51.

Jones, L. D., and Jefferson, I. (2012). "Expansive Soils.” ICE manual of geotechnical engineering. Volume 1, geotechnical engineering principles, problematic soils and site investigation, 413-441.

Montoya, B., DeJong, J., Boulanger, R., Gerhard, R., Ganchenko, A., and Chou, J.-C. (2012). "Liquefaction Mitigation Using Microbial Induced Calcite Precipitation.” GeoCongress.

De Muynck, W., Debrouwer, D., De Belie, N., and Verstraete, W. (2008). "Bacterial carbonate precipitation improves the durability of cementitious materials." Cement and Concrete Research.

Nelson, J. D., and Miller, D. (1992). "Expansive soils Problems and Practice in Foundation and Pavement Engineering." John Wiley and Sons Inc.

Nemati, M., and Voordouw, G. (2003). "Modification of porous media permeability, using calcium carbonate produced enzymatically in situ." Enzyme and Microbial Technology.

van Paassen, L. A., Ghose, R., van der Linden, T. J. M., van der Star, W. R. L., and van Loosdrecht, M. C. M. (2010). “Quantifying Biomediated Ground Improvement by Ureolysis: Large-Scale Biogrout Experiment.” Journal of Geotechnical and Geoenvironmental Engineering, 136(12), 1721-1728.

Petry, T. M., and Little, D. N. (2002). "Review of Stabilization of Clays and Expansive Soils in Pavements and Lightly Loaded Structures-History, Practice, and Future.” Journal of Materials in Civil Engineering, 14(6), 447-460.

Puppala, A. J., and Pedarla, A. (2017). "Innovative ground improvement techniques for expansive soils.” Innovative Infrastructure Solutions, 2(1), 24.

Puppala, A. J., Punthutaecha, K., and Vanapalli, S. K. (2006). "Soil-water characteristic curves of stabilized expansive soils.” Journal of Geotechnical and Geoenvironmental Engineering.

Stocks-Fischer, S., Galinat, J. K., and Bang, S. S. (1999). “Microbiological precipitation of CaCO3.” Soil Biology and Biochemistry, 31(11), 1563-1571.

Torsvik, V., Goksoyr, J., and Daae, F. L. (1990). “High Diversity in DNA of Soil Bacteria.” Applied and Environmental Microbiology, 56(3), 782-787.

Wenderoth, D. F., Rosenbrock, P., Abraham, W. R., Pieper, D. H., and H??fle, M. G. (2003). “Bacterial community dynamics during biostimulation and bioaugmentation experiments aiming at chlorobenzene degradation in groundwater.” Microbial Ecology, 46(2), 161-176.

Whiffin, V. S., van Paassen, L. A., and Harkes, M. P. (2007). "Microbial carbonate precipitation as a soil improvement technique.” Geomicrobiology Journal. 